\title{
Surfaces
}

\section{Portraits de Femmes Palestiniennes édité par Orayb Najjar et Kitty Warnock, Introduction de Mary Sayigh. (Salt Lake City: University of Utah Press, 1992), 372 pages}

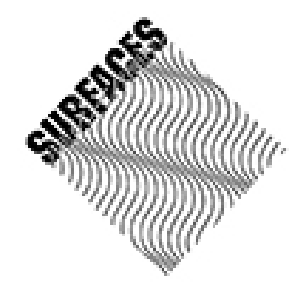

\section{Martha Khoury}

Volume 2, 1992

URI : https://id.erudit.org/iderudit/1065242ar

DOI : https://doi.org/10.7202/1065242ar

Aller au sommaire du numéro

Éditeur(s)

Les Presses de l’Université de Montréal

ISSN

1188-2492 (imprimé)

1200-5320 (numérique)

Découvrir la revue

Citer ce compte rendu

Khoury, M. (1992). Compte rendu de [Portraits de Femmes Palestiniennes édité par Orayb Najjar et Kitty Warnock, Introduction de Mary Sayigh. (Salt Lake City: University of Utah Press, 1992), 372 pages]. Surfaces, 2.

https://doi.org/10.7202/1065242ar d'utilisation que vous pouvez consulter en ligne. 
COMPTE RENDU

ORYAB NAJJAR ET KITTY WARNOCK: PORTRAIT DE FEMMES PALESTINIENNES

Martha Khoury

\begin{abstract}
Portraits de Femmes Palestiniennes édité par Orayb Najjar et Kitty Warnock, Introduction de Mary Sayigh. (Salt Lake City: University of Utah Press, 1992), 372 pages.
\end{abstract}

Cet essai lève le voile sur la femme palestinienne qui n'arrête pas de se battre pour pouvoir assumer pleinement son rôle dans la société à travers la lutte nationale. Orayb Najjar précise, dans sa préface, que ce livre ne se veut pas un livre sur le mouvement national de la femme palestinienne, ni sur le conflit israélo-arabe, mais une source pour comprendre ces deux volets à la fois. L'originalité de l'oeuvre réside dans la double culture de ses auteures, Najjar du côté arabe et Warnock du côté occidental, qui permet d'intéresser aussi bien ceux qui connaissent le problème que ceux qui ne le connaissent pas. L'introduction fait le point sur la marche historique de la femme palestinienne, des territoires occupés jusqu'à la diaspora. Elle sert de toile de fond à tout l'ouvrage.

Dans les six chapitres qui suivent, Najjar fait parler vingt et une femmes palestiniennes, musulmanes et chrétiennes, qui témoignent de leur interaction dans les divers domaines et sur tous les fronts à partir de leurs "histoires de vie". Il s'agit d'un choix de femmes représentant toutes les facettes de la femme palestinienne. Le maximum de situations est couvert dans leurs récits. On retrouve des femmes issues de tous les milieux palestiniens, de tous les niveaux et de différentes générations dont une, "Marie Shéhadé", qui relate des souvenirs de lutte datant de la période ottomane.

Un empirisme anthropologique des plus difficiles à réaliser, car les auteures ont le mérite d'avoir su passer du discours oral au texte tout en demeurant 
fidèles au message lui-même. Le discours vivant s'accompagne de gestes et d'intonations qui donnent à la parole un ton très particulier. Il est normal que ces éléments soient négligés, mais la tentative des auteures de rendre dans l'écriture ces éléments affectifs démontre un souci d'objectivité qu'elles ont su, en outre, concrétiser, en introduisant dans le discours les photos de femmes prises dans différents champs d'activités et en indiquant sous chacune d'elles leur nom. De ce fait, la photo devient un élément constitutif du discours lui-même. Nous pouvons dire que Orayb Najjar et Kitty Warnock ont réussi à exprimer une culture à travers une autre sans annuler, mutiler ou déformer l'authenticité de l'expression. La distorsion du sens et de l'émotion en passant d'une langue à l'autre est minimisée: le lecteur ressent un effet de résonnance d'une culture à l'autre. Pour une fois, la traduction ne trahit pas; elle refond le texte pour le faire resurgir dans la culture nord américaine. Les auteures sont parvenues à trouver les équivalents lexicaux et syntaxiques pour restituer non seulement le message mais aussi le jeu de langage dans lequel il est communiqué. Najjar a pu intégrer avec succès des chants populaires cités et improvisés par une des femmes. Ces chants portent une connotation culturelle très pertinente et leur traduction est d'autant plus difficile qu'il s'agit du parler populaire. En outre, l'élaboration du texte, qui implique le découpage des séquences et leur montage en un récit continu, est soigneusement faite, de manière à intensifier la densité de l'information. L'ordre suivi est tantôt chronologique tantôt thématique. Dans certains cas, Najjar a dû retourner sur le terrain afin d'actualiser les événements. Les auteures ont également réussi à trouver le groupe cible des vingt et une femmes palestiniennes, vingt et une fenêtres dans le voile, ce qui représente un tableau assez complet. La rigueur de l'analyse permet au lecteur de comprendre à quel point la femme palestinienne, en quête de sa réalisation, doit franchir une série d'obstacles. Orayb Najjar dit: "La femme palestinienne est vue comme le symbole de la Terre (bien qu'elle n'en possède pas), elle est appelée "soeur des hommes" en signe de son courage, pourtant elle est éclipsée par eux jusqu'à l'oubli. L'obstacle de l'occupation n'en est pas moindre mais il se présente parmi d'autres tels "la fertilité", "le mariage arrangé", "la tradition", etc."

Les auteures ont réussi à capter la vivacité, la simplicité et le charme du langage de la femme palestinienne, ce qui rend le livre facilement abordable, car il se lit comme un roman. Tous ceux et celles qui s'intéressent à l'aventure de la femme palestinienne, et des femmes en général, trouveront dans ce livre un plaisir esthétique, professionnel et sociopolitique.

Enfin il contient des illustrations et des notes explicatives destinées à l'usage de tous les publics, des plus profanes aux plus informés. Les lecteurs y trouveront aussi une bibliographie riche et détaillée.

\section{Martha Khoury}

\section{Département de Littérature comparée}

\section{Université de Montréal}

